\title{
人体の形の標準化と分類方法
}

\author{
信州大学阵維学部 清水義雄・汪 進・近田淳雄 \\ 東京家政大学家政学部 寺田恭子・雲田直子・神田和子
}

\section{NEW METHODS ON STANDARDIZATION AND CLUSTERING OF HUMAN BODY FOR APPAREL ENGINEERING.}

\author{
By Yoshio Shimizu*1, Jin Wang ${ }^{* 1}$, Atsuo Konda ${ }^{* 1}$, Kyoko Terada ${ }^{* 2}$, \\ Naoko Kumota ${ }^{* 2}$ and Kazuko Kanda ${ }^{* 2}$ \\ * 1 (Faculty of Textile Science and Technology, Shinshu University, Toki- \\ da, Ueda-shi, Nagano-Ken, 386) \\ *2 (Faculty of Home Economics, Tokyo Kasei University, Kaga, Itabashi- \\ Ku, Tokyo, 173)
}

Progress of computer aided engineering (CAE) for apparel industry is slow as compared with other fields, for instance, electric, machinery and chemical industries. The CAE for apparel has been partially developed in computer grading, computer marking, computer cutting systems and so on. The most of production process for apparel industry is still dependent on manual works. This is due to difficulty of material handling and body model for the computer system of apparel production.

Therefore, it is important to investigate the human body form for apparel engineering. In this paper, various problems regarding human body forms were studied and new methods for data reduction, representation and standardization of the human body form were explained. Furthermore, the cluster analysis of the human body form was proposed by means of power spectrum.

The method of low-pass filther was effective in data reduction. The standardization of the human body form using linear transformation of Fourier coefficient agreed approximately with the sensation of our visual feeling for forms. The cluster analysis was useful in grouping the human body form.

(Received November 29, 1988)

\section{1. はじめに}

あらゆる産業分野で CAE (Computer Aided Engineering) 化が進み,コンピュータ支援技術が重要 な役割を果たしている。しかし，被服産業の様な分野に おいては，CAE 化は遅れており，型紙の自動ダレーデ イング等一部の工程を除いて，未だにそのはとんどが人 手によっている。その原因として，被服自体が柔らか く，ハンドリングが困難で形が特定できないということ

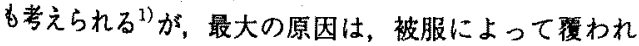
る人体の形が複雑であり，生産工程全体の基整となる精 密な生産モデルが作りにくいという事情がある。 被服造形システムのための人体の研究としては，(1)人
体測定, (2)測定データの圧縮, (3)標準人体の作成, (4)人 体の形の分類等が行われる必要がある。(1)については， 従来身長, 胸囲等の個別の測定值に依っていた。それに 対して人体全体の三次元測定にモアレ等高線法 2 が用い られたが、まだ十分にそのデータを利用するに至ってい ない。また，光を用いた非接触三次元測定法により，迅 速かつ正確に人体測定ができるようになっだー7゙が, 測定データが膨大なため，(2)のデータ圧縮の問題が生じ てきている。(3)と(4)については，従来の個別の測定值を 各々平均化して標準人体を求めたり，多变量解析し比較 分類を行う等の研究がなされている ${ }^{8)-13) 。 ~}$

本報告では，二次元データではあるが，シルエッター による人体写真を用いて，次のような方法を提案した。 
すなわち，(2)のデー夕圧縮に関しては，ローパスフィル ターを施す方法を応用し，人体の形のデータ压縮を行っ た。(3)の標染人体についてた従来の方法とは全く異なっ た複素フーリ工保数の重み付き平均化法を提案し, 人体 の形全体の標準化・平均化を試みた。(4)については，パ ワースペクトルによる形のクラスター分析の方法を提案 した。(3)・(4)で提案する方法は，人体の形を全体的に処 理する点に拉いて今までにない独自のものであり，人体 の研究洨かりでなく，他の分野にも応用が期待される。

\section{2. 人体の形のデータ圧樎および標準化と分類の方 法}

\section{1 被硢者および人体の形の測定方法}

被験者は，19から20才の女子大生100人である。被験 者は水着を着用し，頭部はキャップでびったりとおさえ た。人体の形としては，今回は二次元の図形を取り扱う こととした。すなわち、シルエッター（日本シルエッタ 一侏製)で，正面および側面から撮影した立位正常姿勢 での人体の写真の輪郭を体の形として用いた。

\section{2 人体の形の圧慗方法}

測定された膨大な生デー夕を圧縮する方法に，生デー 夕にスペクトル分析を施しローパスフィルターを施す方 法 $^{14)}$, B-spline 曲線フィッティングを行う方法 ${ }^{15)}$ ，二次 元フーリエ係数による方法 ${ }^{16)}$ 等が示されている。本報 ではデータ王縮に上坂の研究によるローバスフィルター

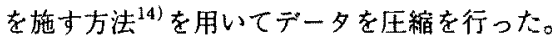

まず、シルエッターによる人体の輪郭の曲線を用いて 次のような処理をした。

形を表現する曲線 C は，長さが 1 に規格化されてい る。平面曲線 C は，複素平面上の曲線 $\mathrm{Z}$ (s)（s 江曲楾

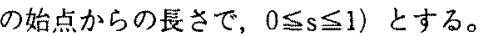

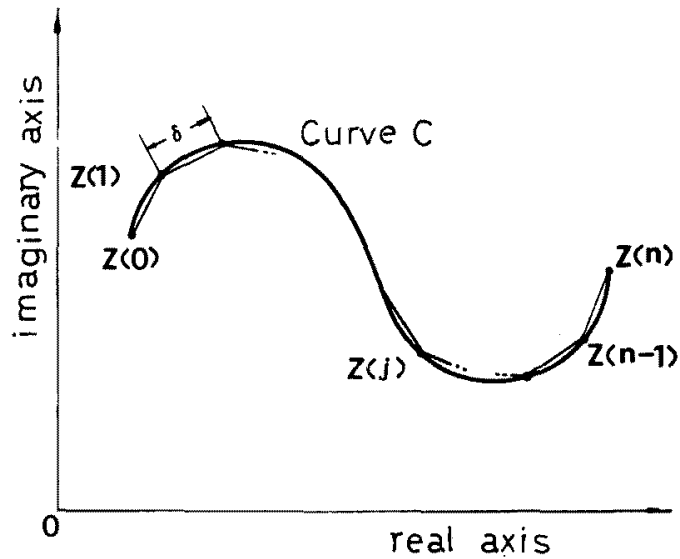

Fig. 1 Representation of a curve C.
以下一定の $\delta に よ っ て, s=j \delta(j=0,1, \cdots, n) 飞$ 散化する。よって曲線 Cは，図 1 に示すことくく、折れ 線図形で近似されている。ここで, $Z\left(j_{\delta}\right)=Z(j)$ とす る。折線単位ベクトル $\mathrm{W}(\mathrm{s})=\mathrm{dZ} / \mathrm{ds}$ は, 離散化によっ $\tau, W(j)(j=0,1, \cdots, n-1)$ となる。従って平面国形 は, $W(\mathrm{j})$ の集合 $|W(\mathrm{j}): \mathrm{j}=0,1, \cdots, \mathrm{n}-1|$ として表 現され，

$$
Z(j)=Z(0)+\delta \sum_{r=0}^{i-1} W(r)
$$

で与えられる。

曲線 C 上を点が移動するに従って，複素数 W(j)梳

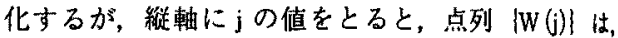
図 2 の様な円简状の軌跡として表せる。

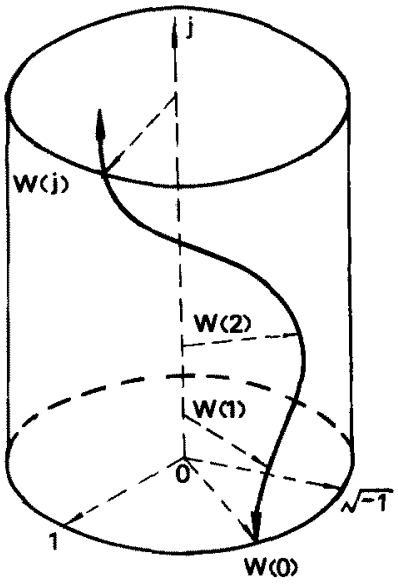

Fig. 2 Representation of a tangential vector.

次に $\mathrm{W}(\mathrm{s})$ の離散化されたフーリ工変換を次式のよう に定義する。

$$
\begin{gathered}
c(k)=\frac{1}{n} \sum_{j=0}^{n-1} W(j) \phi_{k}(j) \\
(k \in S, S=\{0,1, \cdots, n-1\}) \\
\text { ここで, } \phi_{k}(j)=\exp (-2 \pi i j k / n), i=\sqrt{-1} \text { であり, } \\
W(j)=\sum_{k=0}^{n-1} c(k) \phi_{k} \cdot(j)
\end{gathered}
$$

である。ここで $\phi_{\mathrm{k}}{ }^{*}(\mathrm{j})$ は $\phi_{\mathrm{k}}(\mathrm{j})$ の複素共役である。

一般に図形は，全体をおおよそ表現する骨格と，細部 を表現する明細とから成り立っていると考えることが きる ${ }^{14)}$ 。今(2)式の $c(k)$ に対して。

$$
\hat{c}(k)= \begin{cases}c(k) & \left(k=0,1, \cdots, \frac{n}{2}\right) \\ c(n+k) & \left(k=-\frac{n}{2}+1, \cdots,-1\right)\end{cases}
$$

と置くと,(3)式は,

$$
W(j)=\sum_{k=-\frac{n}{2}+1}^{\frac{n}{2}} \hat{c}(k) \phi_{k} \cdot(j)
$$




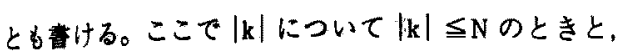
$|\mathrm{k}|>\mathrm{N}$ のときの二つの部分に分けて $\mathrm{W}(\mathrm{j})$ を表すと，

$$
\begin{aligned}
& W_{N}(j)=\sum_{|k| \leqslant N} \hat{c}(k) \phi_{k} \cdot(j) \\
& \widetilde{W}_{N}(j)=\sum_{|k|>N} \hat{N}(k) \phi_{k} \cdot(j)
\end{aligned}
$$

(6)式は図形の骨格に対応し，(7)式は図形の明細に対応 すると考えられる。(6)式を $\mathrm{N}$ 次骨格，(7)式を $\mathrm{N}$ 次明細 と言う。Nの値を適当に選択することにより図形の概略 をN次骨格として圧縮できる。

\section{3 人体の形の合成と標準化の方法 ${ }^{17}$}

(3)式蚁 2 の様な円筒上の図形が，いくつかの周波数 の円筒上のスパイラル曲線の合成として表されることを 示している。

今, $\mathrm{m}$ 個の平面図形 $\mathrm{A}_{1}, \mathrm{~A}_{2}, \cdots \mathrm{Am}$ に対して，それ ぞれのフーリエ係数 $c_{\alpha}(\mathrm{j})(a=1, \cdots, \mathrm{m})$ の重み入によ る線形結合

$$
\mathrm{C}_{\mathrm{s}}(\mathrm{k})=\sum_{\alpha=2}^{m} \lambda_{\alpha} \mathrm{C}_{\alpha}(\mathbf{k})
$$

をフーリエ保数とする図形 $\mathrm{W}_{\mathrm{s}}(\mathrm{j})$ を図形 $\mathrm{A}_{1}, \mathrm{~A}_{2}, \cdots \mathrm{Am}$ の合成図形と言う。

$$
W_{s}(j)=\sum_{k=1}^{n-1} C_{s}(k) \phi_{k} \cdot(j)
$$

この様な方法で異なる图形の合成を行うことは今まで なされておらず、新しい图形の表現形式として重要であ る。重み係数入に種々な值を与えることによって，従来 表現できなかった様々な図形の表現が可能となる。

\section{4 分類の方法}

フーリエ你数の次数の違いにより，图形は骨格と明細 に分けて考えられることを前述した。このことから，フ 一リ土保数は，形の特徴把握に有用であると考えられ る。また, フーリエ係数の絶対值の 2 乗であるパワース ペクトルも、形の特徴を把握するのに有用と考えられ る。そこで，本報では，パワースペクトルを用いて，人
体の形の分類を行った。

パワースペクトル $\mathrm{P}(\mathrm{k})$ を(10)式によって定義する。

$$
\mathrm{P}(\mathrm{k})=|\hat{\mathrm{c}}(\mathrm{k})|^{2} \quad(\mathrm{k}=0, \pm 1, \pm 2, \cdots) \quad(10)
$$

図 3 に示したように，高域のパワースペクトルが急激 に減少しているので，本報ではパワースペクトルの次数

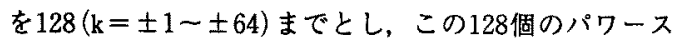
ペクトルを変量とするクラスター分析を行った。

クラスタ一分析の方法は，様々な方法があるが、ここ では階層的クラスター分析の手法 ${ }^{18)}$ を用いた。分類の 基となる距離には，ユークリッド平方距離，標準化ユ一 クリッド平方距離、マアハラノビス距離等があるが, 本報 では，主としてユークリッド平方距離を用い，最大距離 法により解析した。

\section{3. 結果および考察}

\section{1 人体の形の圧樎}

図 3 に，人体の正面シルエットのパワースペクトル例 を示す。 $\mathrm{k}$ の絶対値の大きな高域の $\mathrm{p}(\mathrm{k})$ 杉，急激に隇 少しているので, 人体のシルエットは, 低域の骨格だけ で元の形が良く再生できると期待される。

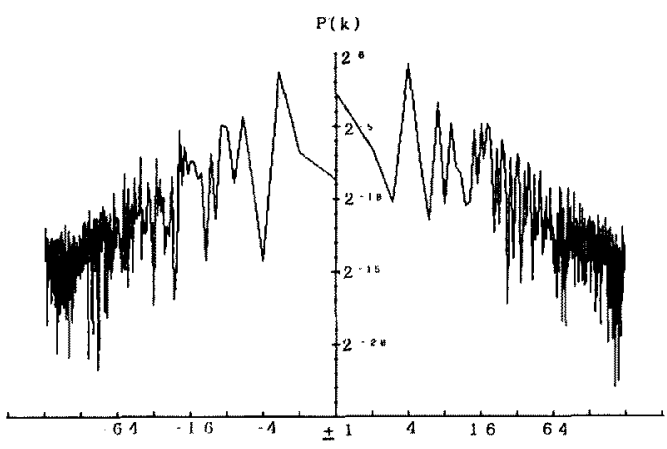

Fig. 3 Power spectrum of human body form.

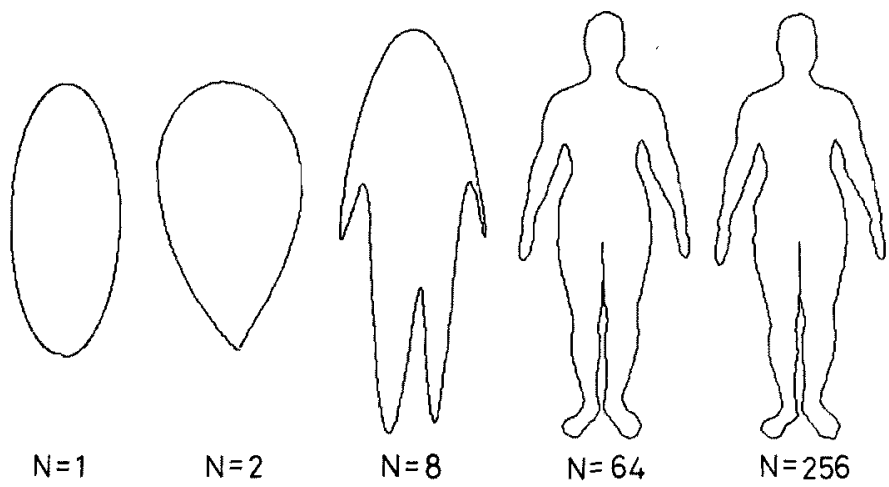

Fig. 4 Representation of human body form with N-dimensional frame. 
図 4 に, 人体のN 次骨格を示す。ローパスフィル夕 一を通して見ると，人体は火の玉の様に，或は幽霊の様 に見える。余り精密なモデルを必要としないときには， $\mathrm{N}=32 \sim 64$ でそれぞれの人体が十分に表現され，N次骨 格によるデータ圧縮が可能である。

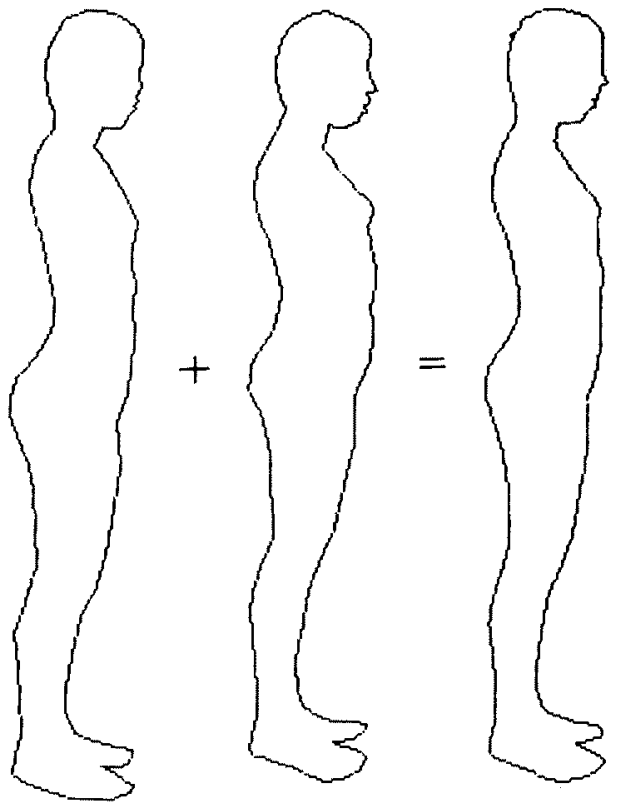

(b)

\section{2 人体の形の合成と标淨化}

図 5 に，異なった人体の形の合成例 $(\mathrm{N}=256)$ を示 す。図 5 (a) では 3 人の被験者の正面のシルエット を, 图 5 (b) では 2 人の被験者の側面のシルエットを 合成したものである。前者は 3 人のシルエットを等分に

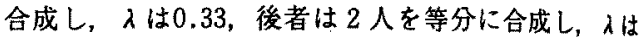

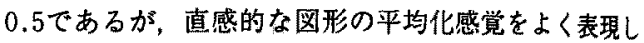
ている。入を変更することにより，何れかの形により類 似したシルエットを得ることができる。例えば，両新か らどの様な子供が生れてくるかを，入を適当に選版こと によって種々に予想してみることは，可能である。

図6（a）に10人の被験者の，図6 (b) に100人の被 験者の人体の形を合成したシルエットを示す。この㭏な 手法を用いれば，大勢の人々の人体合成を行い，標準的 な体型を予想することが可能である。ここで，われわれ が示す人体の形の標準化とは，現実の人体の形を示すの ではなく，あくまでも標準化した人体モデルのことであ る。今後は，この標準人体モデルを基準人体とし，現実 の人体と比較することにより，各人体の特徴抽出を行う ことができる。

\section{3 人体の形の分類}

次に人体の形の分類結果を示す。100人中からランダ ムに取り上げた10人の被験者のシルエットを図7に示 す。このデータをクラスター分析したデンドログラムを 図 8 に示す。このデンドログラムの枝の長さは, ユーク リッド平方距離に対応しており，低い場所で枝別れが存

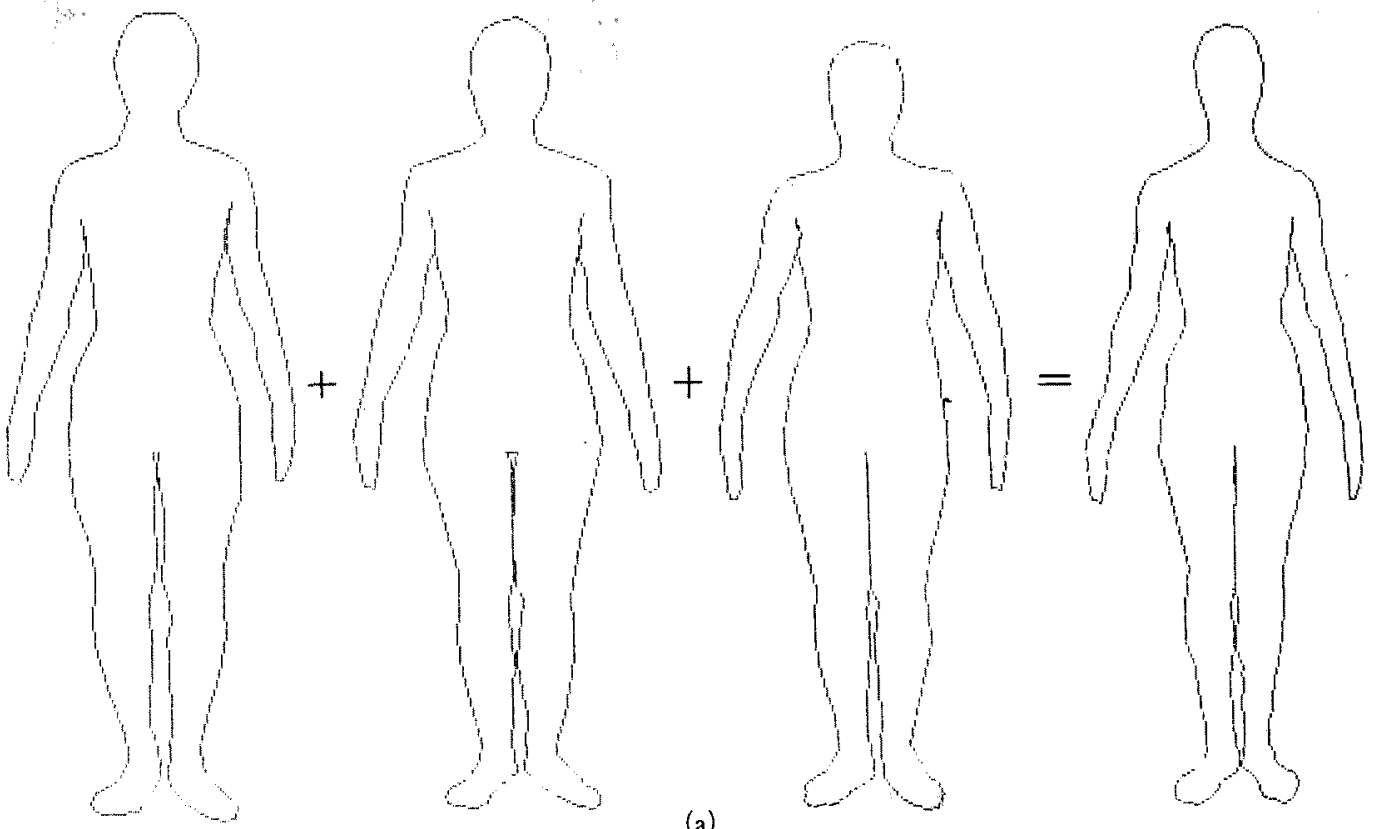

Fig. 5 Example of standardization from human body forms. 


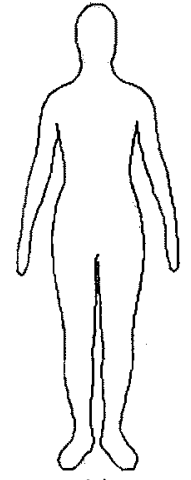

(a)

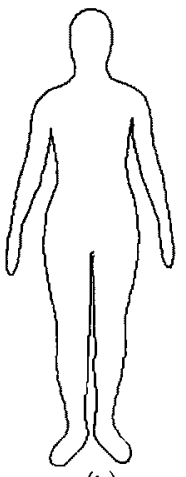

(b)
Fig. 6 Standardization from human body forms. (a) From 10 subjects. (b) From 100 subjects.
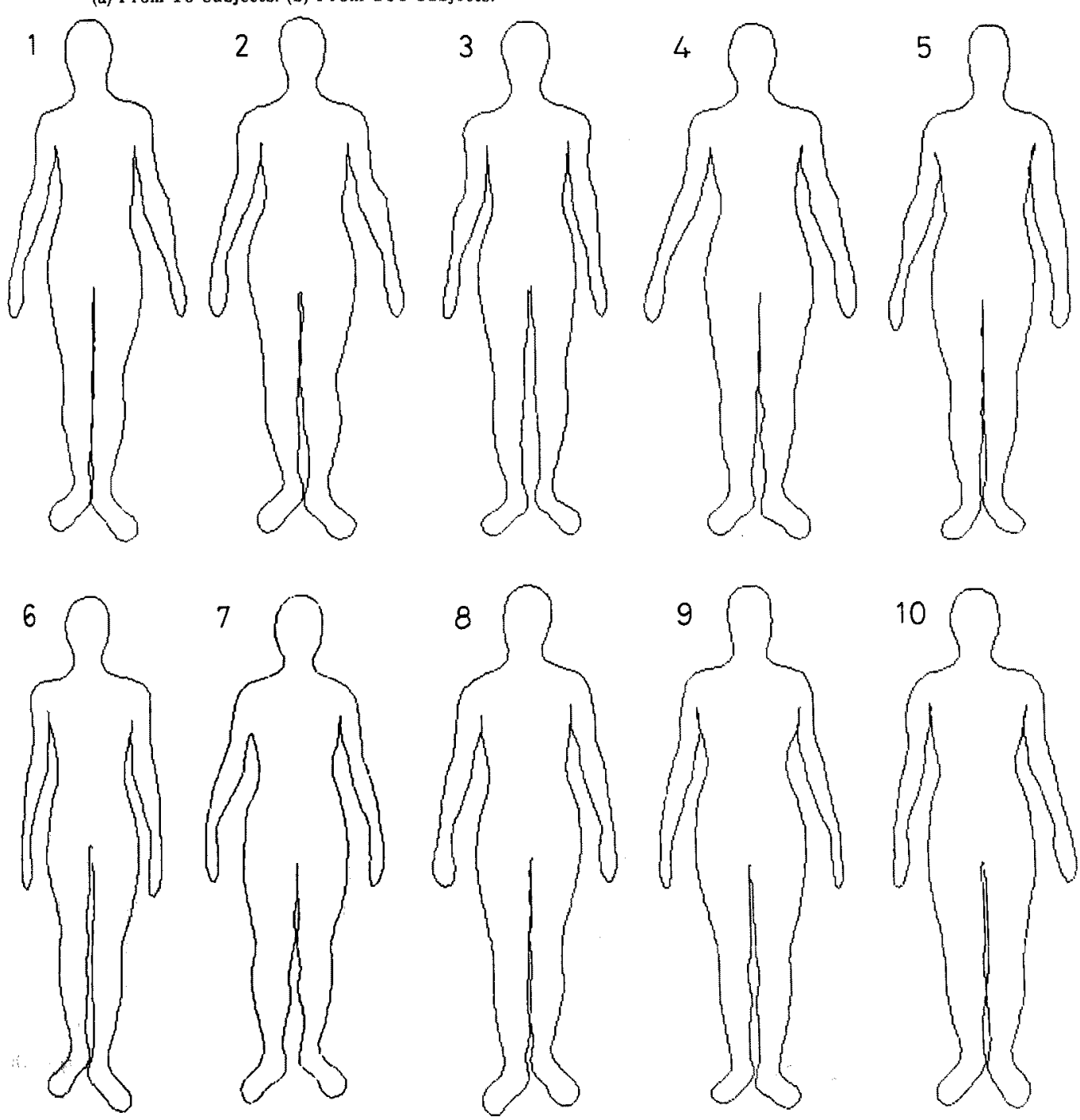

Fig. 7 Human body forms using cluster analysis in Fig. 8 .

在している組合せ程，形が類似しているといえる。この ンドログラムにより，この10人は $(1,2 ， 4 ， 7)$, られる。そのなかでも No. 2 上 4 が最も似ていることを 示している。この結果は，図 7 に示す人体の形から，人 間の目で分類した結果とよく一致している。すなわち， 体の太さを考えると，普通の体型はNo. 1，No. 2, No. 4 およびNo. 7 , 細い体型はNo. 3 と No. 6 , 太い 体型はNo. 5, No. 8，No.9 およびNo.10に分けるこ とができる。さらに局所的に考虑し，用，首，哃部，足 と手の部分の形によって類別すると，No. 2 と No. 4 は 最も類似していると考えられる。

図 9 に，100人のデータのクラスター分析した結果を 


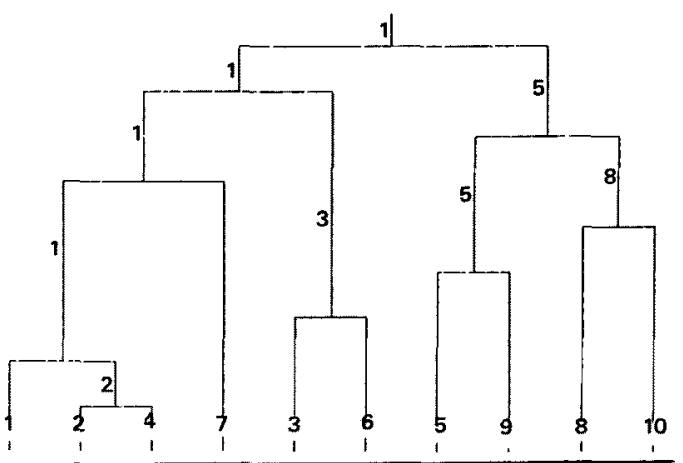

Fig. 8 Dendrogram of cluster analysis for 10 subjects.

示す。この結果より，100人のシルエットは, 少数の構 成単位からなる小さいクラスターやそれが含まれる多数 の構成単位からなるクラスターに分かれていることがわ かる。最も枝の長さが短い組合せは，図 90 No.26と No.27の組合せであるが，図10にこれらのシルエットを 示す。人間の目でも，上く類似していることがわかる。 また、これらが含まれる大きなグループは，例えば，図 9 のデンドロクラムの枝を点線のところで切ると、A か らFの6つのグループに分類される。分類された各グ ループの特徴は, 通常われわれが行っている太ってい

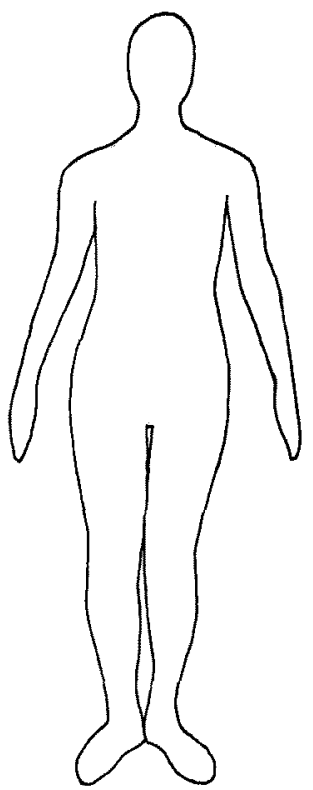

No. 26

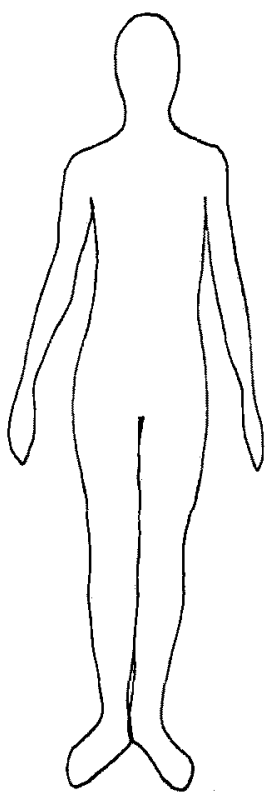

No. 27
Fig. 10 A pair of human body form which has the least Squared Euclidean Distance in the cluster analysis.

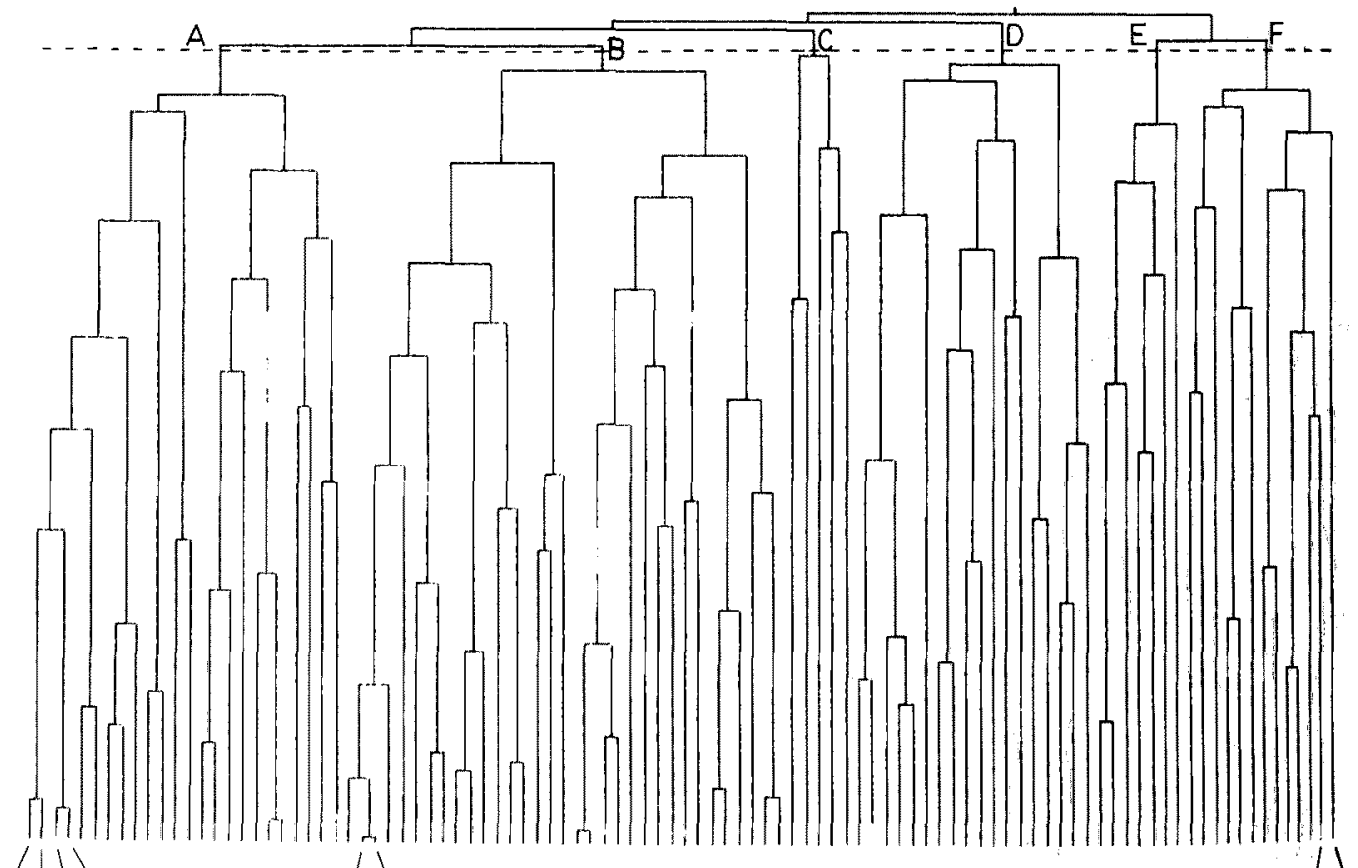

Fig. 9 Dendrogram of cluster analysis for 100 subjects. 
る,やせている，足が長い，下半身が大きい。用が張っ ている等の特隻とは必ずしも一致していない。人間の視 党は，より强く特徽が現われている部分に注目されやす いが，ここで行ったパワースペクトルによる類似度（非 類柋度)は，人間の視覚よりもより総合的な比較の結果 と考えられる。

人間の䅐賞による分類との関係については，さらに詳 しい研究を行う必要がある。この点については，現在ク ラスター分析による人体の分類と特徽抽出について，標 準化した人体の形を用いた新しい方法を検討中である。 さらに，人体全体にわたる解析のみではなく，局部と 加，膘部とかの人体の各部位をそれぞれ解析し，人体全 体と併せて检副する予定である。

\section{4. あとがき}

本報では，人体の形のデータ圧樎の方法および人体の 形の合成法・標準化の方法を提案した。また，人体の形 のパワースペクトルによるクラスター分析を用いて，分 類方法の检矿も行った。

その結果，デー夕圧縮に N 次骨格の表現方法が有効 であることが分かった。

また，線形給合による形の合成法は，直感的な人間の 形の平均化に近いと考えられる。この方法は，合成の際 に合成の重み保数を様々に変化させることによりさらに 一般化して形の合成を行うことができる。この様な手法 を用いれば，大聟の人々の人体合成を行い，標準的な体 型を想定することが可能である。今回は二次元の人体シ ルエットを用いて検討したが，現在はさらに，三次元の 人体にここのような手法の適用を行っている。 クラスター分析による人体の形の分類方法性，人間の 梘覚による結果とほは一致していると考えられるが，大 きなタループ分けについては，さらに検討の必要があ る。現在パワースペクトルに代えて複素フーリエ係数を 用いた形のクラスター分析を检討中である。

我タは，以上に示した方法によって，平均的な標準人 体モデルを作り，このモデルと測定人体のデータとの比 䡈により，各白の人体特徽表現と人体の形の分類を行う 予定である。

付記：この研究の一部は，昭和62年度の織維学会年次
大会において発表した。

謝辞：この仕事を始めるに当たって，東京理科大学の 上坂吉則先生並びに統計数理研究所の種村正美先生に は，貫重な御数示を頂きました。また，ローザ工芸侏に は，体の測定等に多大な便宜を拉計り頂きました。心か ら感謝致します。

\section{文献}

1) 石川欣造，計測と制御，27，763 (1988)

2）芦沢玖美，堤江美子，柳澤澄子，家政誌，30，183 (1979)

3）米国サイバーウェア研究所, 高速三次元デジタイジ ング・システムカタログ

4）中小事業団公開普及説明会資料，“人間工学応用人 体計測解析利用システム”

5）オージー情報システム侏，三次元形状計測装置力夕 ログ

6）工学社エンジニアリング(㸬,，三次元形状測定装置力 タログ

7）清水義雄, 東京家政大学紀要，25，223 (1985)

8）柳澤澄子，解剖学雑誌，33，539（1958）

9) 間壁治子, 家政誌，28，223 (1977)

10）井上和子，柳澤澄子，家政誌，29，32（1978）

11）川上梅，長谷部ヤ工，家政誌，31，507 (1980)

12）高部啓子, 松山容子, 秋月光子，九鬼種美, 植竹桃 子，磯田浩，柳澤澄子，家政誌，38，999（1987）

13）柳澤澄子，鈴木啓子，伊藤令子，清水薰，家政誌， 19, 130 (1968)

14）上坂吉則, 数理科学, 246, 38 (1983)

15）広田源太郎，黑川隆夫，中野広，篠崎章夫，第 3 回 NICOGRAPH 論文コンテスト，p.275 (1987)

16）今逆春樹, 渋谷惊夫, 第15回轼維工学研究討論回資 料, p.33 (1986)

17）清水義雄, 汪進, 近田淳雄, 鳥海浩一郎, 大安和 涁，鳥羽栄治，形の科学会第12回シンポジウム予稿 集, p.31:(1988)

18) Michel R. Anderberg, "Cluster Analysis for Applications", Academicpress. New York, (1973) 